\title{
Community-based Participatory Research
}

\section{Opportunities, Challenges, and the Need for a Common Language}

I n January of 2002, a call for papers featuring community-based participatory research (CBPR) was issued. The intent was to highlight the outstanding work being done in this area and the role CBPR can play in improving the care and outcomes of populations at-risk. ${ }^{1}$ What emerged from this call was more than what any of the editors expected, and has been illustrative of both the superb scholarship and community engagement occurring in CBPR and how much more can be done in refining and broadening the application of CBPR in what we do. The body of research submitted for consideration also highlights several important realities: 1) CBPR is appropriate and applicable across disciplines and within many diverse community settings; 2) the potential for CBPR to make meaningful contributions to improving the health and well-being of traditionally disenfranchised population groups and communities is very real and, in many instances, being realized; and 3) we need to do a better job of articulating CBPR to our peers and colleagues as "research-plus" that is both methodologically rigorous and that makes unique contributions not possible using other means.

The 11 original research papers presented in this Special Issue came from an impressive pool of 81 submissions. And while CBPR may seem somewhat straightforward in theory, as these articles demonstrate, the degree to which CBPR is applied and how it is represented are far more diverse and varied. The peer review process and several editor meetings for this Special Issue brought out many of the challenges inherent in CBPR. How do we define community? What is a meaningful impact? How do we distinguish between communityplaced and community-based research? How do we balance the importance of the research process with the importance of the research product or findings? Is there a methodologic threshold with which to determine whether a project is or is not CBPR? What is evident from the submissions is how broadly CBPR is being applied, geographically, within specific population groups and clinical scenarios, and methodologically.

For example, Angell et al. ${ }^{2}$ and Stratford et al. ${ }^{3}$ both describe CBPR projects in rural settings, while van Olphen et al., ${ }^{4}$ Horowitz et al., ${ }^{5}$ and Masi et al. ${ }^{6}$ all describe urbanbased research. Initiatives targeting specific vulnerable or at-risk populations are featured in work by Lauderdale et al. ${ }^{7}$ with older Chinese immigrants, by Lam et al. ${ }^{8}$ with Vietnamese-American women, and by van Olphen et al. with African-American women. Similarly, CBPR was clearly applicable in several different clinical scenarios, including chronic disease management of diabetes, ${ }^{5}$ asthma, ${ }^{9}$ and cancer treatment and prevention. ${ }^{10}$ The partners engaged in the community-based research also varied across projects and included faith-based organizations, ${ }^{4,10}$ neigh592 borhood and community leaders, ${ }^{6,8}$ and social service and support agencies. ${ }^{2,3,7}$ Finally, the research topics and interventions themselves also reflected a wide spectrum of CBPR applications. Sloane et al. examined the degree of nutritional resources available within a community, whereas Masi et al. evaluated the application of internetbased technologies. ${ }^{5,11}$

The articles presented also reflect the broad scope of research in which CBPR can be applied methodologically. Angell et al. and Corbie-Smith et al. report on findings where CBPR was applied to randomized controlled trials, ${ }^{2,10}$ while van Olphen et al., Masi et al., and Lam et al., all report data from intervention studies with prepost comparisons. ${ }^{4,6,8}$ Horowitz et al. and Lauderdale et al. represent good examples of CBPR applied to survey research, ${ }^{5,7}$ and Parker et al. demonstrate CBPR applied to a qualitative study. ${ }^{9}$ Finally, the article by Nyden provides an overview of CBPR and highlights many of the issues and struggles to institutionalizing and legitimizing CBPR within the broader research community from an academic perspective. $^{12}$

As the science and field of CBPR advance to the next level, it is clear that several things need to occur. We need more formal training in CBPR that is more broadly available to both academically-based researchers and community members. Post-doctoral training programs such as the Kellogg Community Scholars Program ${ }^{13}$ need to be expanded beyond the current 3 schools of public health, and need to be integrated into other health professional schools and within other established fellowship and post-doctoral training programs. Additionally, career development awards sponsored by federal agencies and private philanthropies need to be amenable to proposals that engage the candidate in CBPR projects and ideally should promote this in their solicitation and review process. We also need to encourage scholarship, not only in the application of CBPR, but also in better understanding the nuances of the model, so that it can truly live up to its potential. This includes developing a common language for describing CBPR-related research in the health services literature, so that it can stand on its own merits and be appreciated for the contributions it brings to the field. One possible framework for this common language is introduced in Table 1 and is meant to serve as a resource for authors considering submission of CBPR projects to peer-reviewed journals. Finally, we need to gain a greater appreciation for CBPR as "research-plus" that is reflected in funding priorities, review criteria, community empowerment, and academic advancement.

In summary, it is best to view this Special Issue as a reflection of both where we are as a research community and where we need to go. The 11 papers ultimately chosen 
Introduction

- What is the problem being studied, including its prevalence? Are there population groups or communities that are disproportionately affected?

- Are the affected communities or population groups historically difficult to reach, poorly understood, or traditionally disenfranchised, making CBPR an appropriate methodology?

- What are the limitations or biases associated with using traditional research techniques in studying the problem? Are these limitations evident in the current body of literature?

- What are the advantages to adopting a CBPR approach to this study?

- State the explicit outcomes intended from this study in terms of (1) advancing the field of knowledge about a particular problem; (2) testing a community-based or targeted intervention; or (3) describing a process for sustaining or translating research findings, interventions, or outcomes within a community.

Methods

Setting and patients

- Describe the study population in terms of how it defines a community. How is it organized or structured? What are the points of contact and means of influence?

- How is the setting for your study or intervention relevant to the community?

Intervention

- What roles did community members, community leaders, or a community board play in each stage of the project, from design and implementation through analysis and interpretation?

- What safeguards were in place to ensure data integrity and methodologic rigor in the study design and implementation? Analysis

- How was a community perspective incorporated into the data analysis and interpretation?

Results

- Describe your results in the context of the stated study objectives, adhering to established standards and practices for presenting scientific data.

- Report both process and outcomes measures related to an intervention, including community-level findings.

- What is happening as a result of this study within the community where the project occurred?

Discussion

- What contributions does your research bring to the field?

- What were the challenges and opportunities specific to adopting a CBPR approach that you encountered during your study?

- How were the results shared with the community?

- How are your findings generalizable to and replicable in other communities, in other settings or circumstances, or to policy makers?

- What limitations need to be considered and how should they be viewed when considering your findings?

for this issue represent a small fraction of the excellent work ongoing in many of our communities. Yet there is much more than can and should be done. As the gap in health access and health outcomes grows wider and is further defined by socioeconomics, race, language, country of origin, and other markers and designations inherent in a multicultural, multiethnic society, we need CBPR to help find the answers and sustainable solutions. - Thomas P. O'Toole, MD, Johns Hopkins University, Baltimore, Md; KAYTURA Felix AARON, MD, Agency for Healthcare Research and Quality, Rockville, Md; MARSHALL H. CHIN, MD, MPH, The University of Chicago, Chicago, Ill; CAROL Horowitz, MD, MPH, Mount Sinai School of Medicine, New York, NY; FrederICK TYson, PhD, National Institute of Environmental Health Sciences, Research Triangle Park, NC.

\section{REFERENCES}

1. Aaron KF, Bass EB. A call for papers: community-based participatory research. J Gen Intern Med. 2002;17:84.

2. Angell KL, Kreshka MA, McCoy R, et al. Development of a psychosocial intervention for rural women with breast cancer. $J$ Gen Intern Med. 2003;18:499-506.

3. Stratford D, Chamblee S, Ellerbrook TV, et al. Integration of a participatory research strategy into a rural health survey. J Gen Intern Med. 2003;18:585-7.

4. van Olphen J, Schulz A, Israel B, et al. Religious involvement, social support, and health among African-American women on the east side of Detroit. J Gen Intern Med. 2003;18: 548-56.

5. Horowitz CR, Williams L, Bickell NA. A community-centered approach to diabetes in East Harlem. J Gen Intern Med. 2003; 18:541-7.

6. Masi CM, Suarez-Balcazar YS, Cassey MZ, Kinney L, Piotrowski $\mathrm{ZH}$. Internet access and empowerment: a community-based health initiative. J Gen Intern Med. 2003;18:524-9.

7. Lauderdale DS, Kuohung V, Chang S-L, Chin MH. Identifying older Chinese immigrants at high risk for osteoporosis. J Gen Intern Med. 2003;18:507-14.

8. Lam TK, McPhee SJ, Mock J, et al. Encouraging VietnameseAmerican Women to obtain Pap tests through lay health worker outreach and media education. J Gen Intern Med. 2003;18: 515-23.

9. Parker EA, Israel BA, Williams M, et al. Community action against asthma: examining the partnership process of a communitybased participatory research project. J Gen Intern Med. 2003;18: 557-66.

10. Corbie-Smith G, Ammerman A, Katz ML, et al. Trust, benefit, 
satisfaction, and burden: a randomized controlled trial to reduce cancer risk through African-American churches. J Gen Intern Med. 2003; 18:530-40.

11. Sloane DC, Diamant AL, Lewis LB, et al. Improving the nutritional resource environment for healthy living through communitybased participatory research. J Gen Intern Med. 2003;18:567-74.
12. Nyden P. Academic incentives for faculty participation in community-based participatory research. J Gen Intern Med. 2003;18: 575-84.

13. Kellogg Community Health Scholars Program. Available at: http://www.sph.umich.edu/chsp/. Accessed February 25, 2003.

\begin{tabular}{|} 
ANNOUNCEMENT \\
You can reach JGIM on the Internet! \\
For more information \\
about submitting manuscripts to JGIM \\
or if you would like to submit a \\
Letter to the Editor or a \\
short creative writing piece \\
for possible publication in the Journal, \\
please e-mail us at \\
jgim@jhmi.edu
\end{tabular}

